\title{
THEORETICAL STUDIES ON THE STRUCTURAL, SPECTROSCOPIC, THERMODYNAMIC, AND ELECTRONIC PROPERTIES OF ZOLEDRONIC ACID
}

\author{
Q.Z. Liu ${ }^{1,2}$, Y. Wang ${ }^{1,2}$, L. Qiu ${ }^{1,2}$, T.F. Wang ${ }^{1,2}$, S.N. Luo ${ }^{1,2}$, H.L. Yuan ${ }^{2}$, J.G. Lin $^{2}$ \\ ${ }^{1}$ School of Chemical and Material Engineering, Jiangnan University, Wuxi, P. R. China \\ E-mail: qiuling@jsinm.org (Ling Qiu) \\ ${ }^{2}$ Key Laboratory of Nuclear Medicine, Ministry of Health \& Jiangsu Key Laboratory of Molecular Nuclear \\ Medicine, Jiangsu Institute of Nuclear Medicine, Wuxi, P. R. China \\ E-mail: linjianguo@jsinm.org (Jianguo Lin)
}

\begin{abstract}
The structure, spectroscopic, thermodynamic, and electronic properties of zoledronic acid (ZL, 1-hydroxy-2-(1H-imidazol-1-yl)ethane-1,1-diyldiphosphonic acid), typical third-generation nitrogen-containing bisphosphonates (N-BPs), have been investigated systematically. Six conformations are taken into account, including three unprotonated and three protonated structures. They are optimized by four different density functional theory (DFT) methods combined with four different basis sets to evaluate their performance in predicting the structural and spectral features of ZL. Thermodynamic properties are calculated based on the harmonic vibrational analysis, including the standard heat capacity $\left(C_{\mathrm{p}, \mathrm{m}}^{0}\right)$, entropy $\left(S_{\mathrm{m}}^{0}\right)$, and enthalpy $\left(H_{\mathrm{m}}^{0}\right)$. The ${ }^{1} \mathrm{H}$ and ${ }^{13} \mathrm{C}$ NMR chemical shifts are calculated using the GIAO method and compared with the experimental data. Molecular electrostatic potential (MEP) and frontier molecular orbital (FMO) analyses are also performed to study the electronic characteristics of the title compound.
\end{abstract}

DOI: $10.15372 / J S C 20150712$

Ke y w o r d s: zoledronic acid, different conformations, spectroscopic properties, thermodynamic properties, electronic characteristics.

\section{INTRODUCTION}

Bisphosphonates (BPs) are known as an important group of drugs which exhibit high affinity to calcified matrices in bones, such as hydroxyapatite (HA) [1]. Therefore, they have been used widely to treat a variety of diseases caused by increasing bone resorption, such as osteoporosis, Paget's disease, hypercalcemia due to malignancy, and bone metastases of several cancers [2-4]. In general, BPs consist of a $\mathrm{P}-\mathrm{C}-\mathrm{P}$ backbone and two side chains $\left(\mathrm{R}_{1}\right.$ and $\left.\mathrm{R}_{2}\right)$ covalently bonded to the middle carbon atom. In the past decades, a great deal of researches have been focused on changing the side chains to get diverse structures and improve biological activities. Up to date, three generations of BPs have been indentified according to their different substituents [5]. The first generation was non-nitrogen BPs, such as clodronate and etidronate. The second generation is characterized by an amino terminal group, including pamidronate, alendronate, and ibandronate. The third generation contains a nitrogen-bearing heterocyclic ring substituted at the side chain, such as zoledronate and risedronate. Due to the better antiresorptive activity of nitrogen-containing bisphosphonates (N-BPs) than non-nitrogen containing BPs [ 6 ], the third-generation $\mathrm{N}-$ BPs have attracted considerable and increasing attention.

Among these BPs, ZL was the most potent one in inhibiting bone resorption and has been widely used in clinical trials. Apart from its role in bone preservation and reduction of skeletal related events,

(C) Liu Q.Z., Wang Y., Qiu L., Wang T.F., Luo S.N., Yuan H.L., Lin J.G., 2015 
preclinical and also clinical evidence suggest that it has a direct anticancer effect [7]. This is mainly associated with the side chains in ZL. One of the two side chains is a hydroxyl group and another is the imidazole ring. In general, the hydroxyl group acts as a "bone hook" and is essential for the efficient bone resorption activity, and the nitrogen-containing imidazole ring inhibits the enzyme farnesyl diphosphonate synthase (FPPS) by binding to its active site via the participation in a cluster consisting of three $\mathrm{Mg}^{2+}$ with the phosphonate groups. In particular, ZL usually acts as a bond "shield" incorporated into the skeleton, attaining therapeutic concentration and thus inhibiting bone resorption by a cellular effect on osteoclast.

It is acknowledged that many physical, chemical, and biological properties of compounds have a connection with their geometric and electronic structures. With the rapid development of computer techniques and computational chemistry, theoretical modeling and calculation have become an effective way to study the structure and properties of various systems at the atomic level as a complement to the experiment. It provides an insight into the electronic structures of compounds and has strongly stimulated the development of traditional experimental chemistry [8]. A suitable quantum chemical study is helpful to clarify experimental phenomena and to economically predict molecular properties. Currently, density functional theory (DFT) has been recognized as a popular approach for the study of the structure, spectra, and electronic properties of compounds [9] and for the efficiency and accuracy with respect to the evaluation of a number of molecular properties [10].

In this work, four different DFT methods with four basis sets were employed to study the structures and spectral properties of ZL. Six conformations were taken into account, including three unprotonated and three protonated structures. The performances of different DFT methods in predicting the geometry and spectra of ZL were investigated, as well as the effect of different basis sets. The second purpose was to investigate the structure and properties of ZL by a more reliable method, including the structure, IR, Raman, and ${ }^{1} \mathrm{H} /{ }^{13} \mathrm{C}$ NMR spectra, thermodynamic properties, electrostatic potential, and frontier molecular orbitals. These results can not only provide basic information for studying the structure-activity relationships of BPs and stimulate experimental investigations on the BPs, but also will be instructive for the design and synthesis of novel potential BPs drugs.

\section{COMPUTATIONAL METHODS}

The crystal structures of ZL determined by X-ray diffraction [11, 12] were used for theoretical computations. Three protonated structures were obtained directly from the Cambridge Crystallographic Data Centre (CCDC), and the unprotonated structures were obtained by modifying the protonated structures with the GaussView5.0 program [13]. All computations were performed using the Gaussian09 software package [14 ]. Four DFT methods, including B3LYP [15 ], LC- $\omega$ PBE [ 16, 17 ], MPW1PW [ 18 ] and PBE1PBE [19], and four different basis sets $\left(6-31 \mathrm{G}^{*}\right.$ [20 ], 6-31+G* [21], $6-311 \mathrm{G} * *[22]$ and $\left.6-311++\mathrm{G}^{* *}[22,23]\right)$ were employed to evaluate the performance of each method in predicting the structural and spectral features of the title compound. Geometries of six different conformations of ZL were fully optimized without any symmetry restriction. To characterize the nature of each stationary point and determine the zero-point vibrational energy (ZPVE) correction, the harmonic vibrational analysis was performed subsequently on each optimized structure at the same level. According to the previous studies, the DFT calculated harmonic vibrational frequencies were usually larger than those observed experimentally, so the scale factors of $0.96,0.95,0.95$, and 0.99 were used to take into account the systematic overestimation of vibrational frequencies in the B3LYP, MPW1PW, PBE1PBE, and LC- $\omega$ PBE calculations respectively [24-27]. Based on the scaled harmonic frequencies, thermodynamic properties were derived by the statistical thermodynamics method [28 ]. The gauge-independent atomic orbital (GIAO) [29, 30 ] method introduced by Wolinski, Hitlon and Pulay [31 ] was used for calculating ${ }^{1} \mathrm{H}$ and ${ }^{13} \mathrm{C}$ magnetic shielding constants of $\mathrm{ZL}$. The relative chemical shifts $(\delta)$ were then estimated using the corresponding shielding constants of TMS (tetramethylsilane) calculated at the same level as the reference $\left(\delta / \mathrm{ppm}=\delta_{\mathrm{TMS}}-\delta_{\text {calc }}\right)$.

To evaluate the accuracy of all the methods for predicting the geometric parameters of the title compound, the overall mean percent deviation $(\Delta)$ was calculated according to the following equation [32]: 


$$
\Delta=\frac{\sum_{i=1}^{n}\left(\left|y_{i}-x_{i} / x_{i}\right|\right)}{n} \times 100
$$

where $y_{i}$ and $x_{i}$ are the theoretical and experimental values of a given parameter, respectively, and $n$ is the number of geometric parameters considered.

To evaluate the accuracy of the predicted vibrational frequencies, the mean unsigned error (MUE, in $\mathrm{cm}^{-1}$ ) was also calculated according to the following equation [16]:

$$
M U E=\frac{\sum_{i=1}^{n}\left|v_{\text {th }}-v_{\exp }\right|}{n}
$$

where $v_{\text {th }}$ is the theoretical vibrational frequency, $v_{\exp }$ is the corresponding experimental frequency, and $\mathrm{n}$ is the number of normal modes considered.

\section{RESULTS AND DISCUSSION}

Molecular structures. The optimized structures of six different conformations of ZL were illustrated in Fig. 1, where IM, IT, and $\mathrm{IT}_{\mathrm{w}}$ denoted the molecular structures taken from the monoclinic (IM) crystal structure, the triclinic (IT) crystal structure without water, and the triclinic (IT) crystal structure with three water molecules, respectively. The symbols " $n$ " (neutral) and " $\mathrm{i}$ " (ionic) represent the unprotonated and protonated zwitterionic forms, respectively. In Table 1, the geometric parameters of six different conformations optimized at the B3LYP/6-31+G* level were listed and compared with the corresponding experimental data.

In comparison with the X-ray data on the monoclinic unprotonated conformation ( $\left.{ }^{\mathrm{n}} \mathrm{IM}\right)$, the difference in the optimized bond lengths was found to be within $0.1 \AA$, except the $\mathrm{O}-\mathrm{H}$ bond lengths of hydroxy groups with the difference increasing to $0.2 \AA$. As for the bond angles, most of them are in good agreement with the experimental data, and the major difference mainly occurs in the phosphonate groups, especially in the $\mathrm{O}-\mathrm{P}-\mathrm{O}$ bond angles within the deviation of $15^{\circ}$. These differences may be due to the fact that the calculated results belong to the single molecule in the gas phase without considering the intermolecular interaction or the environment effect of peripheral molecules, while the experimental data are obtained in the crystal filed and intermolecular interactions make the bond lengths shorten, and hence, make them difficult to stretch. This also implies that intermolecular interactions play an important role in determining the structure and properties of the compounds.

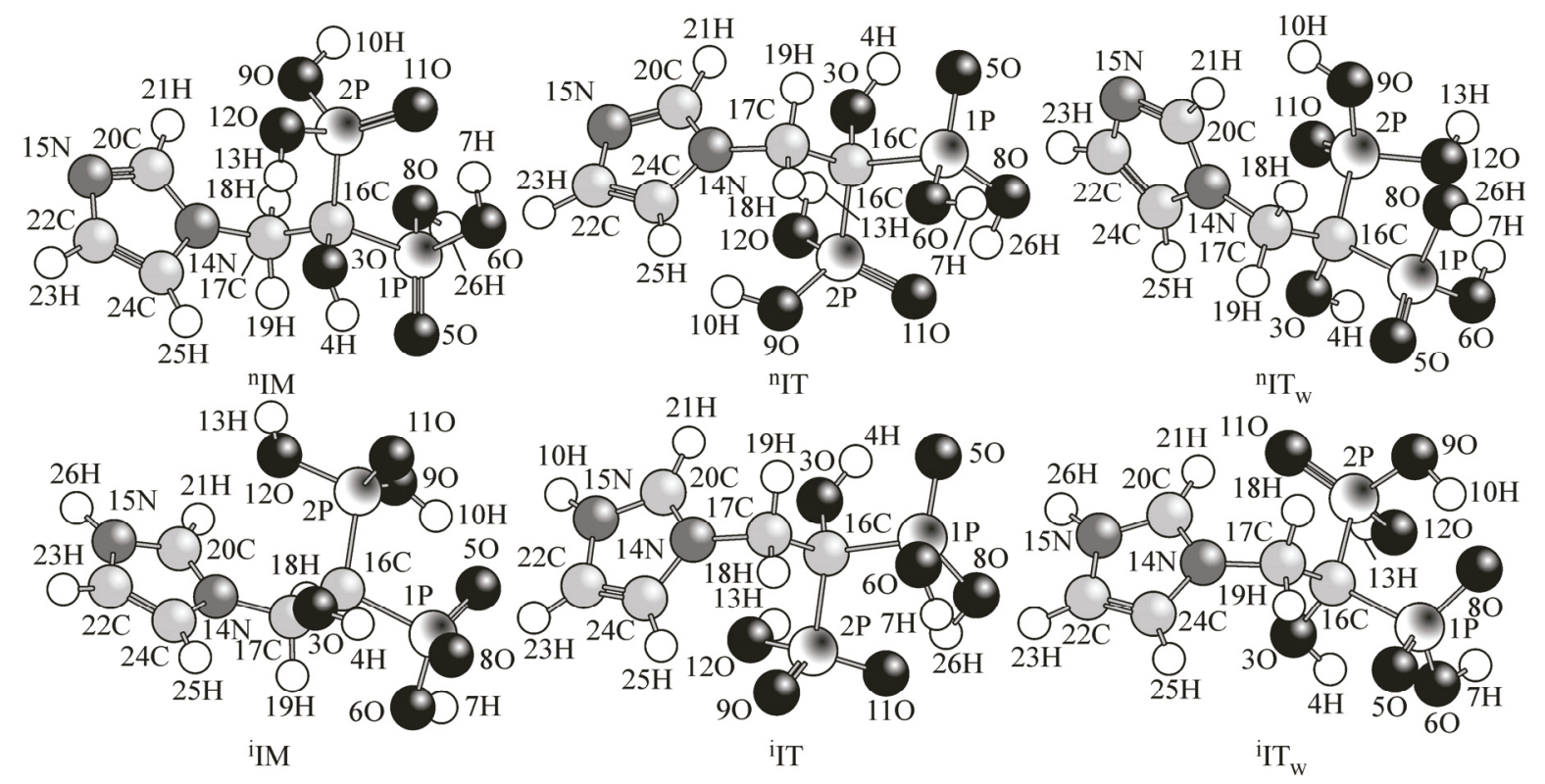

Fig. 1. Optimized structures of six ZL conformations at the relatively accurate calculation level along with the atomic numbering 
Optimized geometric parameters of Six ZL conformations at the B3LYP/6-31+G* level

\begin{tabular}{|c|c|c|c|c|c|c|c|c|c|}
\hline Parameter & Exp. ${ }^{a}$ & ${ }^{n} \mathrm{IM}$ & í IM & Exp. ${ }^{b}$ & "IT & iT & Exp. ${ }^{b}$ & ${ }^{n} I T_{w}$ & ${ }^{\mathrm{i}} \mathrm{IT}_{\mathrm{w}}$ \\
\hline \multicolumn{10}{|c|}{ Bond length, $\AA$} \\
\hline $\mathrm{P} 1-\mathrm{O} 5$ & 1.516 & 1.487 & 1.521 & 1.498 & 1.489 & 1.493 & 1.513 & 1.480 & 1.495 \\
\hline $\mathrm{P} 1-\mathrm{O} 6$ & 1.549 & 1.593 & 1.663 & 1.554 & 1.624 & 1.629 & 1.569 & 1.616 & 1.664 \\
\hline $\mathrm{P} 1-\mathrm{O} 8$ & 1.498 & 1.627 & 1.500 & 1.548 & 1.592 & 1.581 & 1.503 & 1.627 & 1.523 \\
\hline $\mathrm{P} 1-\mathrm{C} 16$ & 1.842 & 1.875 & 1.929 & 1.858 & 1.877 & 1.880 & 1.860 & 1.880 & 1.933 \\
\hline $\mathrm{P} 2-\mathrm{O} 9$ & 1.544 & 1.613 & 1.605 & 1.505 & 1.601 & 1.503 & 1.522 & 1.620 & 1.585 \\
\hline $\mathrm{P} 2-\mathrm{O} 11$ & 1.522 & 1.499 & 1.483 & 1.527 & 1.493 & 1.525 & 1.501 & 1.482 & 1.503 \\
\hline $\mathrm{P} 2-\mathrm{O} 12$ & 1.552 & 1.599 & 1.655 & 1.555 & 1.609 & 1.651 & 1.563 & 1.642 & 1.632 \\
\hline $\mathrm{P} 2-\mathrm{C} 16$ & 1.847 & 1.869 & 1.875 & 1.856 & 1.885 & 1.898 & 1.845 & 1.889 & 1.870 \\
\hline $\mathrm{N} 14-\mathrm{C} 17$ & 1.476 & 1.452 & 1.485 & 1.472 & 1.458 & 1.479 & 1.470 & 1.454 & 1.484 \\
\hline $\mathrm{N} 14-\mathrm{C} 20$ & 1.333 & 1.375 & 1.331 & 1.340 & 1.371 & 1.334 & 1.328 & 1.376 & 1.335 \\
\hline N14-C24 & 1.370 & 1.387 & 1.385 & 1.372 & 1.391 & 1.386 & 1.376 & 1.385 & 1.384 \\
\hline $\mathrm{N} 15-\mathrm{C} 20$ & 1.336 & 1.314 & 1.340 & 1.324 & 1.317 & 1.340 & 1.328 & 1.315 & 1.342 \\
\hline $\mathrm{N} 15-\mathrm{C} 22$ & 1.362 & 1.379 & 1.385 & 1.359 & 1.375 & 1.385 & 1.357 & 1.379 & 1.385 \\
\hline \multicolumn{10}{|c|}{ Bond angle, deg. } \\
\hline $\mathrm{O} 5-\mathrm{P} 1-\mathrm{O} 6$ & 109.5 & 113.7 & 106.2 & 113.6 & 117.1 & 112.1 & 107.7 & 113.7 & 109.6 \\
\hline $\mathrm{O} 5-\mathrm{P} 1-\mathrm{O} 8$ & 115.0 & 116.2 & 126.6 & 112.7 & 113.8 & 118.9 & 116.0 & 115.4 & 124.8 \\
\hline $\mathrm{O} 5-\mathrm{P} 1-\mathrm{C} 16$ & 109.7 & 109.6 & 107.6 & 112.5 & 108.1 & 106.0 & 105.9 & 114.5 & 106.3 \\
\hline $\mathrm{O} 6-\mathrm{P} 1-\mathrm{O} 8$ & 114.0 & 107.7 & 110.2 & 108.2 & 107.3 & 105.5 & 112.3 & 106.1 & 108.1 \\
\hline $\mathrm{O} 6-\mathrm{P} 1-\mathrm{C} 16$ & 102.7 & 108.2 & 101.9 & 104.9 & 100.1 & 106.0 & 104.9 & 103.8 & 97.1 \\
\hline $\mathrm{O} 8-\mathrm{P} 1-\mathrm{C} 16$ & 105.0 & 100.3 & 101.6 & 104.3 & 109.5 & 107.6 & 109.3 & 102.0 & 107.3 \\
\hline $\mathrm{O} 9-\mathrm{P} 2-\mathrm{O} 11$ & 114.1 & 112.5 & 120.5 & 111.2 & 111.4 & 123.9 & 114.0 & 115.5 & 114.1 \\
\hline $\mathrm{O} 9-\mathrm{P} 2-\mathrm{O} 12$ & 114.0 & 101.8 & 100.1 & 112.2 & 102.5 & 108.7 & 109.1 & 101.9 & 106.9 \\
\hline $\mathrm{O} 9-\mathrm{P} 2-\mathrm{C} 16$ & 103.6 & 106.9 & 102.6 & 110.5 & 109.9 & 105.8 & 106.7 & 107.2 & 105.2 \\
\hline $\mathrm{O} 11-\mathrm{P} 2-\mathrm{O} 12$ & 107.0 & 117.9 & 110.9 & 110.4 & 117.9 & 108.2 & 112.3 & 114.2 & 111.9 \\
\hline $\mathrm{O} 11-\mathrm{P} 2-\mathrm{C} 16$ & 112.4 & 112.2 & 115.1 & 109.6 & 111.1 & 105.9 & 109.0 & 115.7 & 115.3 \\
\hline $\mathrm{O} 12-\mathrm{P} 2-\mathrm{C} 16$ & 105.4 & 104.3 & 105.9 & 102.6 & 103.4 & 102.1 & 105.3 & 100.5 & 102.3 \\
\hline $\mathrm{C} 17-\mathrm{N} 14-\mathrm{C} 20$ & 125.8 & 126.6 & 125.3 & 128.2 & 128.0 & 124.8 & 125.8 & 125.3 & 126.8 \\
\hline $\mathrm{C} 17-\mathrm{N} 14-\mathrm{C} 24$ & 124.7 & 127.1 & 125.6 & 123.1 & 125.8 & 125.8 & 125.2 & 128.2 & 124.1 \\
\hline $\mathrm{C} 20-\mathrm{N} 14-\mathrm{C} 24$ & 109.5 & 106.2 & 109.0 & 108.6 & 106.2 & 109.0 & 109.0 & 106.3 & 109.1 \\
\hline $\mathrm{C} 20-\mathrm{N} 15-\mathrm{C} 22$ & 108.7 & 105.3 & 109.2 & 109.6 & 105.4 & 109.4 & 109.1 & 105.2 & 109.8 \\
\hline $\mathrm{P} 1-\mathrm{C} 16-\mathrm{P} 2$ & 114.4 & 112.5 & 107.0 & 114.1 & 113.2 & 112.6 & 114.3 & 116.0 & 112.1 \\
\hline
\end{tabular}

${ }^{\mathrm{a}}$ Experimental data were taken from [12 ]. $\quad{ }^{\mathrm{b}}$ Experimental data were taken from [ 11$]$.

A comparison of the monoclinic and triclinic structures shows that there are two obvious differrences. One is the opposite orientation of the imidazole ring, and the other is the hydrogen atom taking part in the proton transfer reaction. For the monoclinic protonated conformation ( $\left.{ }^{\mathrm{I}} \mathrm{IM}\right)$, in which the N15 nitrogen atom was protonated by the $\mathrm{H} 26$ hydrogen atom originally bonded with the O8 oxygen atom, the $\mathrm{P} 1-\mathrm{O} 8$ bond type changed from a single bond to a double bond and the bond length decreased by about $0.12 \AA$, whereas the N15-C20 bond length increased by $0.03 \AA$. Due to this proton transfer reaction, the increments for the $\mathrm{O} 5-\mathrm{P} 1-\mathrm{O} 8$ and $\mathrm{O} 6-\mathrm{P} 1-\mathrm{O} 8$ bond angles were nearly $10^{\circ}$ and that for the $\mathrm{C} 20-\mathrm{N} 15-\mathrm{C} 22$ angle was about $4^{\circ}$, whereas the decrement for the $\mathrm{O} 8-\mathrm{P} 1-\mathrm{C} 16$ bond angle was nearly $6^{\circ}$. For the triclinic structures without water molecules (IT), the P2-O9 bond length has a slightly larger change (about $0.1 \AA$ ), but the double $\mathrm{N} 15-\mathrm{C} 20$ bond changes little (about $0.03 \AA$ ) . On the whole, the changes in the $\mathrm{C}-\mathrm{N}-\mathrm{C}$ bond angles are about $4^{\circ}$ and those in the $\mathrm{O}-\mathrm{P}-\mathrm{O}$ bond angles are the largest (about $10^{\circ}$ ). This may be also due to the fact that the effect of intermolecular interactions was not taken into account in the theoretical calculations. For the triclinic struc- 


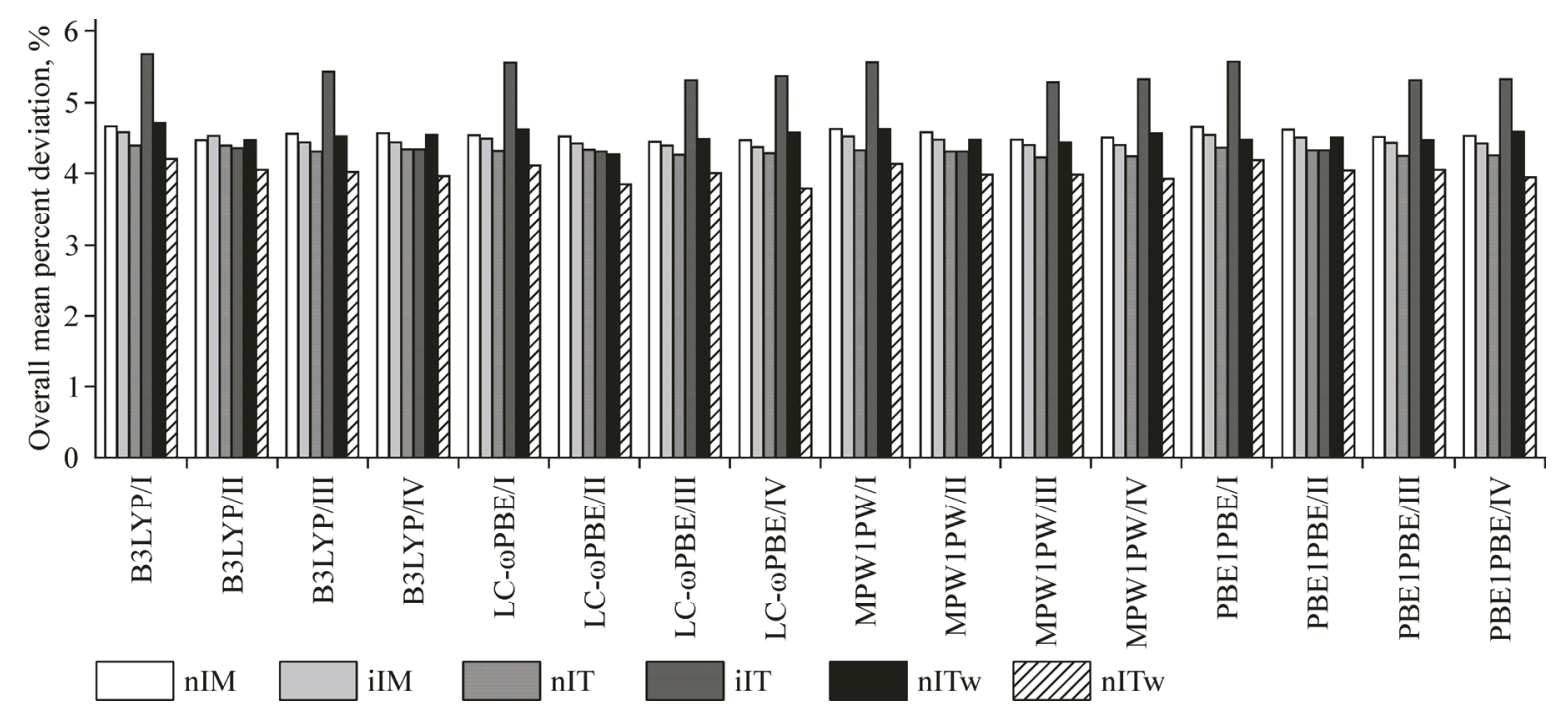

Fig. 2. Comparison of the calculation accuracy of different methods. The $6-31 G^{*}, 6-31+G^{*}, 6-311 G^{* *}$, and $6-311++\mathrm{G}^{* *}$ basis sets were denoted as I, II, III, and IV, respectively

tures with three water molecules $\left(\mathrm{IT}_{\mathrm{w}}\right)$, its unprotonated and protonated conformations are both differrent from those of the IT structures, not only in the existence of water molecules but also in the orientations of substituents. Here, it should be pointed out that during the optimization of unprotonated and protonated $\mathrm{IT}_{\mathrm{w}}$ conformations of $\mathrm{ZL}$ in the present work, water molecules were deleted for clarity. A comparison of the optimized unprotonated and protonated $\mathrm{IT}_{\mathrm{w}}$ conformations $\left({ }^{\mathrm{n}} \mathrm{IT}_{\mathrm{w}} \mathrm{Vs}^{\mathrm{i}} \mathrm{IT}_{\mathrm{w}}\right.$ ) also showed that when the $\mathrm{H} 26$ proton transferred from the $\mathrm{O} 8$ oxygen atom to the $\mathrm{N} 15$ nitrogen atom, the $\mathrm{P} 1-\mathrm{O} 8$ bond length was found to decrease by about $0.1 \AA$ and the N15- C20 bond length was found to increase by about $0.03 \AA$. At the same time, the $\mathrm{O} 5-\mathrm{P} 1-\mathrm{O} 8$ bond angle increased remarkably (about $10^{\circ}$ ) and $\mathrm{O} 8-\mathrm{P} 1-\mathrm{C} 16$ increased by about $5^{\circ}$ due to the decreased steric hindrance on the $\mathrm{O} 8$ oxygen atom.

In order to get a better computational method, the overall mean percent deviation $(\Delta / \%)$ was calculated according to Eq.(1), which was used as a criterion to judge the performance of methods in predicting the structural parameters. From Fig. 2, it is found that all the deviations are very close on the whole, and those for the protonated structures are smaller than those for the unprotonated structures. except for the structure of ${ }^{\mathrm{i}} \mathrm{IT}$. At the same calculation level, the smallest deviation is for the ${ }^{\mathrm{i}} \mathrm{IT}_{\mathrm{w}}$ and the greatest one is for ${ }^{\mathrm{i}} \mathrm{IT}$. From a careful comparison of the overall mean percent deviations obtained at all the levels, the LC- $\omega$ PBE method was found to produce the smallest deviation and the second was B3LYP, and the $6-31+\mathrm{G}^{*}$ and $6-311++\mathrm{G}^{* *}$ basis sets can give better results for predicting the geometric parameters of the unprotonated and protonated structures, respectively.

In addition, from the calculated energy of six conformations at all the levels, it is found that the energies of protonated structures are lower than those of the unprotonated structures by about 25 $40 \mathrm{~kJ} \cdot \mathrm{mol}^{-1}, 2-10 \mathrm{~kJ} \cdot \mathrm{mol}^{-1}$, and $20-45 \mathrm{~kJ} \cdot \mathrm{mol}^{-1}$ for IM, IT, and $\mathrm{IT}_{\mathrm{w}}$, respectively. Therefore, it is deduced that the stability of the protonated conformations is higher than that of the unprotonated ones, which coincides well with the experimental fact that protonated BPs can often be obtained in the chemical synthesis.

Spectroscopic properties. In this section, the IR, Raman, and NMR spectra of six conformations were calculated and analyzed in detail. It should be pointed out that the LC- $\omega$ PBE method cannot produce the Raman intensity due to the limitation of this functional as implemented in the Gaussian09 program [16] that cannot perform the calculation of polarizability derivatives. Thus, only the IR and NMR spectra were calculated for ZL by the LC- $\omega$ PBE functional. To the best of our knowledge, the IR spectrum of ZL has not been described in detail in any publication due to the complexity of its structure. Based on the observed IR [33 ] and Raman spectra [34 ], the vibrational bands of ZL were simulated and analyzed in detail in the present work. According to the rule of (3N-6) normal modes where $\mathrm{N}$ is the number of atoms in the molecule, ZL possesses 72 vibrational normal modes since it has 

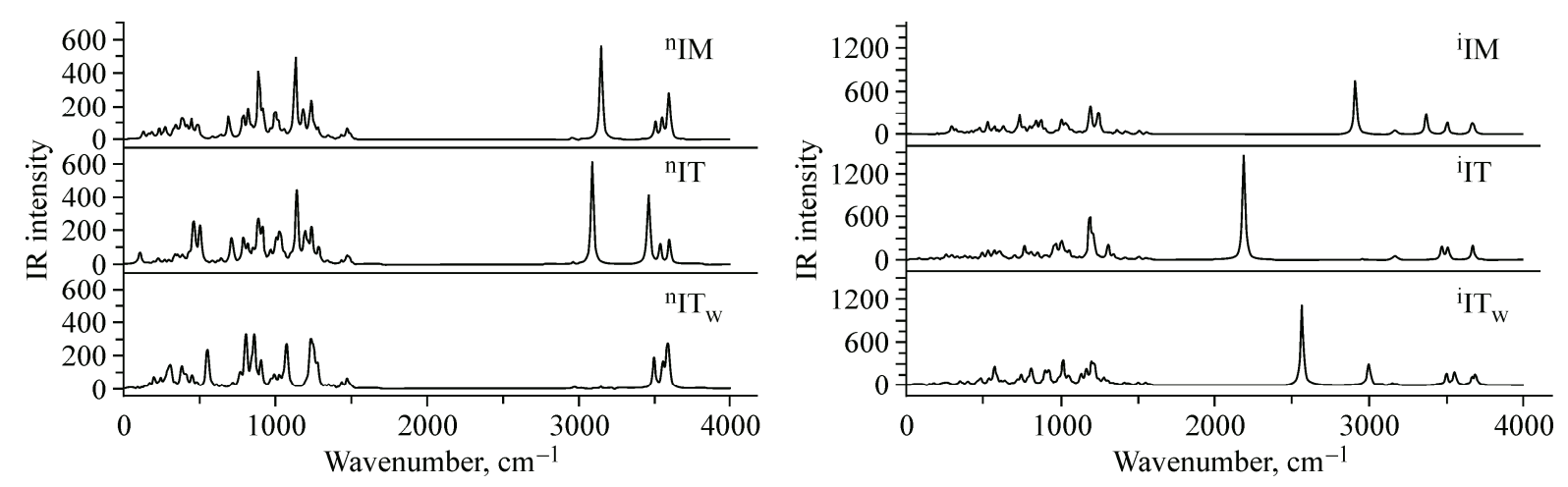

Fig. 3. Simulated IR spectra of the unprotonated and protonated structures of ZL

26 atoms. Here, only the strong and distinguished vibrational modes were analyzed and assigned in detail.

In order to evaluate the accuracy of each functional and basis set in predicting the vibrational frequencies of ZL, the mean unsigned error (MUE) was calculated based on the experimental and theoretical data. On the whole, the smaller the basis set used, the lower the MUE produced for the unprotonated structures. For the protonated structures, however, the larger basis set leads to the lower MUE value. Combining with the overall mean percent deviation $(\Delta)$ for the optimized geometry, a relatively precise method can be obtained to accurately predict the geometry and vibrational spectrum of ZL. For the unprotonated structures, B3LYP/6-31+G* is the best method for predicting its conformational and spectral properties, while B3LYP/6-311++G** is the better method for the protonated structures. Hence, all subsequent calculations were performed at these two levels respectively.

Fig. 3 shows the IR spectra of the unprotonated and protonated structures simulated at the B3LYP/6-31+G* and B3LYP/6-311++G** levels, respectively. For the unprotonated and protonated structures of IM, it was noted that the frequencies moved to the low wave numbers when a proton transfer reaction took place. There was no obvious change in the IR intensity except for the peaks at $700-1200 \mathrm{~cm}^{-1}$. For the structures of IT, there were no evident changes in the frequencies and the intensities of the bands less than $2100 \mathrm{~cm}^{-1}$. However, in the range of high wave numbers, the peak at $2200 \mathrm{~cm}^{-1}$ moved to $3050 \mathrm{~cm}^{-1}$ and the IR intensity doubled, and the intensity for the wave number $3500-3700 \mathrm{~cm}^{-1}$ became weaker than that for the unprotonated structure. For the structure of $\mathrm{IT}_{\mathrm{w}}$, two new peaks appeared in the IR spectrum of the protonated structure at $2600 \mathrm{~cm}^{-1}$ and $3000 \mathrm{~cm}^{-1}$, and the intensities were stronger than those in the unprotonated structure. The major difference for the unprotonated structures is that there is no peak for $\mathrm{IT}_{\mathrm{w}}$ at $3100 \mathrm{~cm}^{-1}$. However, for the protonated structures, the major difference is the shift of the peaks.

The hydroxyl stretching and bending bands are very broad and strong, and can be identified easily due to the extent of hydrogen bonding. For the title compound, there are two types of $\mathrm{O}-\mathrm{H}$ stretching vibrations. One is $\mathrm{P}-\mathrm{OH}$ in the phosphonic acid groups, and the other is $\mathrm{C}-\mathrm{OH}$. The wave numbers of both hydroxyl groups locate over $3200 \mathrm{~cm}^{-1}$, but the latter is smaller than the former by about $100 \mathrm{~cm}^{-1}$. Since the imidazole ring is aromatic, the $\mathrm{C}-\mathrm{H}$ vibrations of the imidazole ring in $\mathrm{ZL}$ occur in the band region $3000-3100 \mathrm{~cm}^{-1}$, and they are assigned to the symmetric and asymmetric stretching vibrations. For the $\mathrm{CH}_{2}$ group in the framework, the asymmetric and symmetric stretching vibrations of $\mathrm{C}-\mathrm{H}$ locate at around $2925 \mathrm{~cm}^{-1}$ and $2850 \mathrm{~cm}^{-1}$, respectively. And the $\mathrm{CH}_{2}$ bending vibration occurs in the region of $1465 \pm 10 \mathrm{~cm}^{-1}$. The $\mathrm{C}=\mathrm{C}$ and $\mathrm{C}=\mathrm{N}$ stretching vibrations generally occur in the regions of $1695-1540 \mathrm{~cm}^{-1}$ and $1690-1590 \mathrm{~cm}^{-1}$, respectively, which are hard to distinguish. The vibrational bands at 1500 and $1550 \mathrm{~cm}^{-1}$ were assigned to the $\mathrm{C}=\mathrm{N}$ and $\mathrm{C}=\mathrm{C}$ stretching vibrations for the unprotonated and protonated structures, respectively. The $\mathrm{P}=\mathrm{O}$ and $\mathrm{P}-\mathrm{OH}$ vibrations were present in most vibrations, so only the primary vibrations were assigned. The stretching bands in the regions of $1350-1250 \mathrm{~cm}^{-1}$ and $1250-1140 \mathrm{~cm}^{-1}$ correspond to the free and associated $\mathrm{P}=\mathrm{O}$ bonds, respectively. The $\mathrm{P}-\mathrm{OH}$ stretching vibrations appeared in the region of $1100-950 \mathrm{~cm}^{-1}$. As compared with 
$\mathrm{T}$ a b 1 e 2

Experimental and calculated ${ }^{1} \mathrm{H}$ and ${ }^{13} \mathrm{C}$ NMR chemical Shifts (ppm) for Six ZL conformations

\begin{tabular}{c|r|r|r|r|r|r|r}
\hline Atom & \multicolumn{1}{|c|}{ Exp. $^{{ }^{2}}$} & \multicolumn{1}{c|}{${ }^{\mathrm{n}} \mathrm{IM}$} & \multicolumn{1}{c|}{${ }^{\mathrm{i}} \mathrm{IM}$} & \multicolumn{1}{c}{${ }^{\mathrm{n}} \mathrm{IT}$} & \multicolumn{1}{c}{${ }^{\mathrm{i}} \mathrm{IT}$} & \multicolumn{1}{c}{${ }^{\mathrm{n}} \mathrm{T}_{\mathrm{w}}$} & ${ }^{\mathrm{i}} \mathrm{IT}_{\mathrm{w}}$ \\
\hline $\mathrm{H} 18$ & 4.60 & 4.52 & 4.46 & 4.42 & 5.07 & 4.20 & 4.38 \\
$\mathrm{H} 19$ & 4.60 & 4.20 & 4.91 & 4.33 & 3.92 & 4.52 & 5.62 \\
$\mathrm{H} 21$ & 7.86 & 7.33 & 8.05 & 7.66 & 8.46 & 6.86 & 12.05 \\
$\mathrm{H} 23$ & 6.99 & 7.01 & 7.02 & 7.14 & 6.94 & 7.06 & 6.91 \\
$\mathrm{H} 25$ & 7.37 & 6.70 & 8.36 & 6.49 & 8.77 & 7.38 & 7.37 \\
$\mathrm{C} 16$ & 79.55 & 80.84 & 82.27 & 80.61 & 80.22 & 85.43 & 80.27 \\
$\mathrm{C} 17$ & 54.00 & 50.40 & 61.91 & 51.91 & 63.23 & 50.96 & 60.46 \\
$\mathrm{C} 20$ & 141.93 & 133.15 & 141.28 & 134.69 & 138.77 & 129.84 & 147.77 \\
$\mathrm{C} 22$ & 124.66 & 127.49 & 121.19 & 128.96 & 120.64 & 128.53 & 120.12 \\
$\mathrm{C} 24$ & 127.72 & 114.27 & 134.65 & 111.71 & 138.20 & 117.24 & 134.60 \\
MUE, \% ${ }^{\mathrm{b}}$ & & 3.16 & 2.33 & 3.24 & 3.08 & 3.69 & 3.00
\end{tabular}

${ }^{\mathrm{a}}$ Experimental NMR chemical shifts were taken from [ 35 ]. ${ }^{\mathrm{b}}$ MUE: mean unsigned error.

the experimental data, most of the vibrations were slightly overestimated. This may be due to that the experimental values are measured in the solid state which contains water molecules or other solvents. On the whole, the theoretical values are in good agreement with the experimental data.

Table 2 lists the calculated ${ }^{1} \mathrm{H}$ and ${ }^{13} \mathrm{C}$ NMR chemical shifts for the unprotonated and protonated conformations of $\mathrm{ZL}$ at the B3LYP/6-31+ $\mathrm{G}^{*}$ and B3LYP/6-311++ $\mathrm{G}^{* *}$ levels, respectively. As compared with the experimental data [35], about a half of the calculated chemical shifts were overestimated. For the protonated structures, the calculated data agree well with the experimental ones and the MUE values are smaller than those of the unprotonated conformations. For the carbon atoms, the largest difference is $13.5 \mathrm{ppm}$ and mostly it is less than $10 \mathrm{ppm}$; and for the hydrogen atoms, most differrences are less than $1 \mathrm{ppm}$. However, there is a special chemical shift at $12.05 \mathrm{ppm}$ for ${ }^{\mathrm{i}} \mathrm{IT}_{\mathrm{w}}$, which is not assigned to the group of the imidazole and it is not reasonable data. On the whole, the calculated values correlate well with the experimental data, which further demonstrates the reliability and suitability of the methods applied.

Thermodynamic properties. Based on the harmonic vibrational analysis, the standard thermodynamic functions for the title compound at different temperatures were obtained, such as the heat capacity $\left(C_{\mathrm{p}, \mathrm{m}}^{0}\right)$, entropy $\left(S_{\mathrm{m}}^{0}\right)$, and enthalpy $\left(H_{\mathrm{m}}^{0}\right)$, which have been shown in Fig. 4 . It is clear that these thermodynamic functions increase with an increase in the temperature. This is due to that the vibrational movement is intensified at a higher temperature and makes more contributions to the thermody namic functions, while at a lower temperature the main contributions to the thermodynamic functions come from the translations and rotations of the molecules.

The quantitative correlations between the thermodynamic properties and the temperature can be expressed by quadratic equations, as listed in Table 3. It is obvious that as the temperature increases, the increments for both $C_{\mathrm{p}, \mathrm{m}}^{0}$ and $S_{\mathrm{m}}^{0}$ decrease but that for $H_{\mathrm{m}}^{0}$ increases constantly. However, since the coefficients of $T^{2}$ are very small, these correlations can be approximated by linear equations. In other words, the thermodynamic functions of the title compound increase linearly with the temperature increasing on the whole. Based on these relationships, one can obtain the $C_{\mathrm{p}, \mathrm{m}}^{0}, S_{\mathrm{m}}^{0}$ and $H_{\mathrm{m}}^{0}$ values at any temperature, which may be helpful for further studies on other physical and chemical properties of the title compound. For example, according to the equation $\Delta G=\Delta H-T \Delta S$, the changes in Gibbs free energies can be calculated for chemical reactions or intermolecular interactions, which will help us to judge the possibility of the spontaneity of the reaction [36].

Other thermodynamic parameters were also studied, such as the zero-point vibrational energy (ZPVE), thermal energy, specific capacity, entropy, and dipole moment. The ZPVE values are similar 

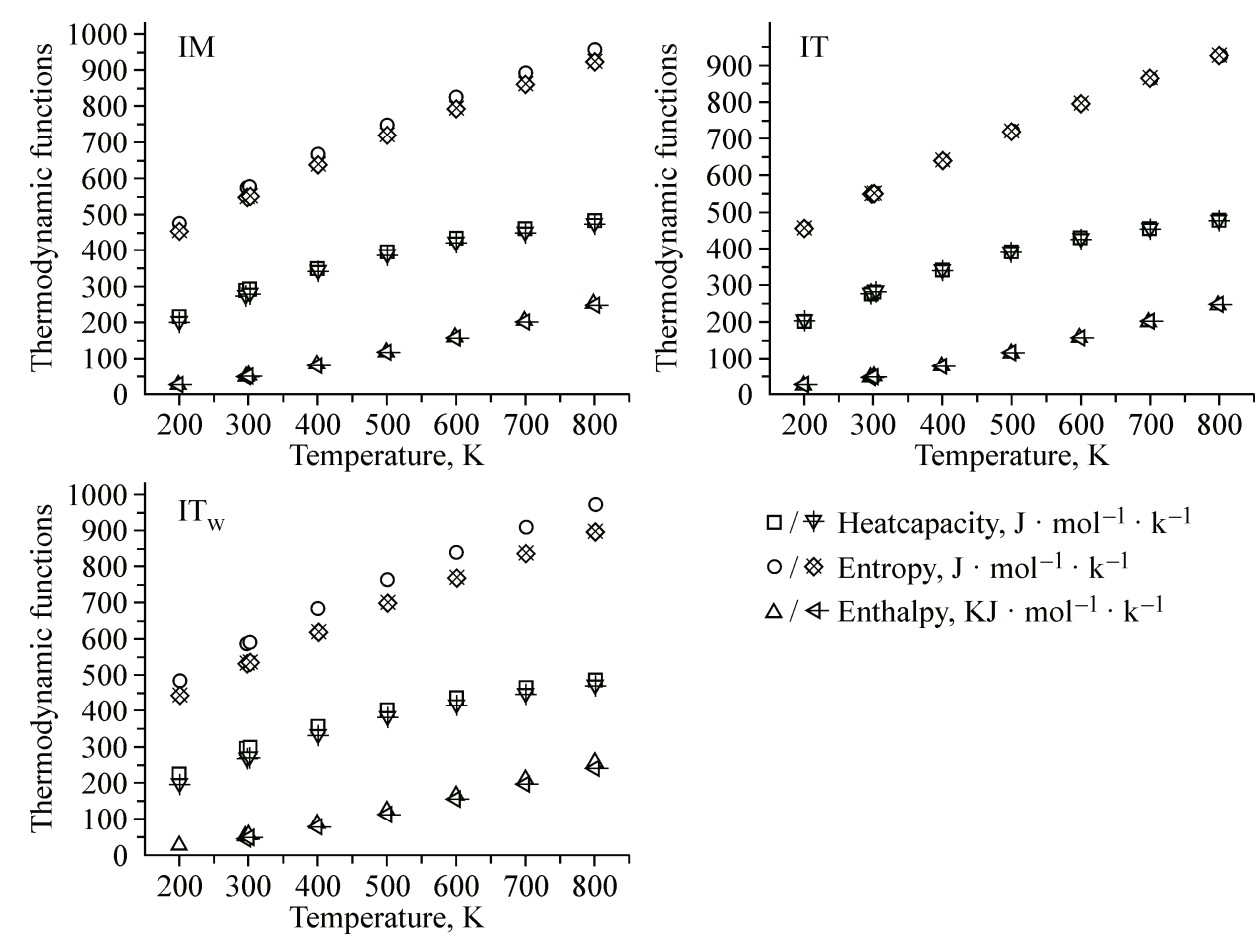

$\square / \$$ Heatcapacity, $\mathbf{J} \cdot \mathrm{mol}^{-1} \cdot \mathrm{k}^{-1}$

$\mathrm{O}$ Entropy, $\mathrm{J} \cdot \mathrm{mol}^{-1} \cdot \mathrm{k}^{-1}$

$\Delta / \varangle$ Enthalpy, $\mathrm{KJ} \cdot \mathrm{mol}^{-1} \cdot \mathrm{k}^{-1}$

Fig. 4. Correlations between the thermodynamic properties and the temperature. Open symbols denote the unprotonated conformations, while open symbols with ' $x$ ' denote the protonated conformations

$\mathrm{T}$ a b 1 e 3

Correlations between the thermodynamic functions and the temperature for Six ZL conformations ${ }^{\text {a }}$

\begin{tabular}{c|l|l|l|l}
\hline \multicolumn{1}{c|}{${ }^{\mathrm{n}} \mathrm{IM}$} & \multicolumn{2}{c}{${ }^{\mathrm{i}} \mathrm{IM}$} \\
$C_{\mathrm{p}, \mathrm{m}}^{0}=-0.0005 \mathrm{~T}^{2}+0.97 \mathrm{~T}+42.15$ & $R^{2}=0.9996$ & $C_{\mathrm{p}, \mathrm{m}}^{0}=-0.0005 \mathrm{~T}^{2}+0.99 \mathrm{~T}+28.46$ & $R^{2}=0.9996$ \\
$S_{\mathrm{m}}^{0}=-0.0004 \mathrm{~T}^{2}+1.17 \mathrm{~T}+252.48$ & $R^{2}=1.0$ & $S_{\mathrm{m}}^{0}=-0.0003 \mathrm{~T}^{2}+1.13 \mathrm{~T}+242.49$ & $R^{2}=1.0$ \\
$H_{\mathrm{m}}^{0}=0.0002 \mathrm{~T}^{2}+0.17 \mathrm{~T}-18.41$ & $R^{2}=0.9998$ & $H_{\mathrm{m}}^{0}=0.0002 \mathrm{~T}^{2}+0.15 \mathrm{~T}-18.00$ & $R^{2}=0.9998$ \\
${ }^{\mathrm{n}} \mathrm{IT}$ & ${ }^{\mathrm{i}} \mathrm{IT}$ & ${ }^{\mathrm{n}} \mathrm{IT} \mathrm{w}_{\mathrm{w}}$ \\
$C_{\mathrm{p}, \mathrm{m}}^{0}=-0.0005 \mathrm{~T}^{2}+0.99 \mathrm{~T}+33.82$ & $R^{2}=0.9995$ & $C_{\mathrm{p}, \mathrm{m}}^{0}=-0.0005 \mathrm{~T}^{2}+0.99 \mathrm{~T}+28.23$ & $R^{2}=0.9996$ \\
$S_{\mathrm{m}}^{0}=-0.0004 \mathrm{~T}^{2}+1.15 \mathrm{~T}+244.55$ & $R^{2}=1.0$ & $S_{\mathrm{m}}^{0}=-0.0003 \mathrm{~T}^{2}+1.13 \mathrm{~T}+244.14$ & $R^{2}=1.0$ \\
$H_{\mathrm{m}}^{0}=0.0002 \mathrm{~T}^{2}+0.16 \mathrm{~T}-18.30$ & $R^{2}=0.9998$ & $H_{\mathrm{m}}^{0}=0.0002 \mathrm{~T}^{2}+0.15 \mathrm{~T}-17.55$ & $R^{2}=0.9998$ \\
$C_{\mathrm{p}, \mathrm{m}}^{0}=-0.0005 \mathrm{~T}^{2}+0.95 \mathrm{~T}+49.07$ & $R^{2}=0.9995$ & $C_{\mathrm{p}, \mathrm{m}}^{0}=-0.0005 \mathrm{~T}^{2}+0.98 \mathrm{~T}+21.19$ & $R^{2}=0.9997$ \\
$S_{\mathrm{m}}^{0}=-0.0004 \mathrm{~T}^{2}+1.19 \mathrm{~T}+254.21$ & $R^{2}=1.0$ & $S_{\mathrm{m}}^{0}=-0.0003 \mathrm{~T}^{2}+1.08 \mathrm{~T}+239.28$ & $R^{2}=1.0$ \\
$H_{\mathrm{m}}^{0}=0.0002 \mathrm{~T}^{2}+0.17 \mathrm{~T}-18.86$ & $R^{2}=0.9998$ & $H_{\mathrm{m}}^{0}=0.0002 \mathrm{~T}^{2}+0.14 \mathrm{~T}-16.95$ & $R^{2}=0.9998$
\end{tabular}

${ }^{\mathrm{a}} C_{\mathrm{p}, \mathrm{m}}^{0}, S_{\mathrm{m}}^{0}$ and $H_{\mathrm{m}}^{0}$ are in $\mathrm{J} \cdot \mathrm{mol}^{-1} \cdot \mathrm{K}^{-1}, \mathrm{~J} \cdot \mathrm{mol}^{-1} \cdot \mathrm{K}^{-1}$ and $\mathrm{kJ} \cdot \mathrm{mol}^{-1}$, respectively.

to each other within the unprotonated $\left(474.31-476.26 \mathrm{~kJ} \cdot \mathrm{mol}^{-1}\right)$ or protonated structures $(480.16$ $482.15 \mathrm{~kJ} \cdot \mathrm{mol}^{-1}$ ), and the former is higher than the latter by about $6 \mathrm{~kJ} \cdot \mathrm{mol}^{-1}$. The dipole moment reflects the molecular charge distribution and is given as a vector in three dimensions. Therefore, it can be used as a descriptor to depict the charge movement across the molecule [37]. Since the dipole moments of the protonated structures $(18.43,13.50$, and 13.91) are all higher than those of the unpro- 

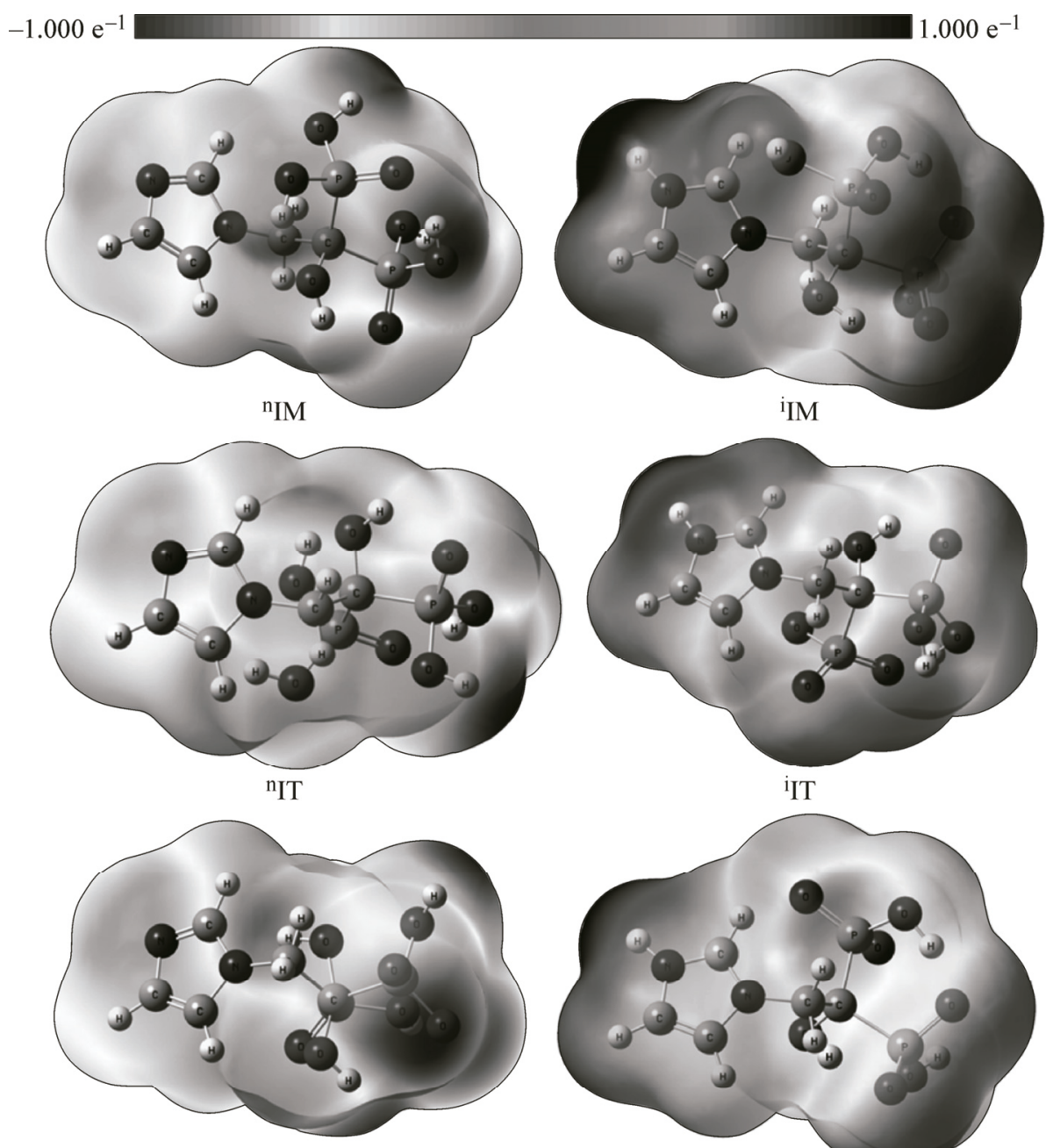

$\mathrm{nIT}_{\mathrm{w}}$

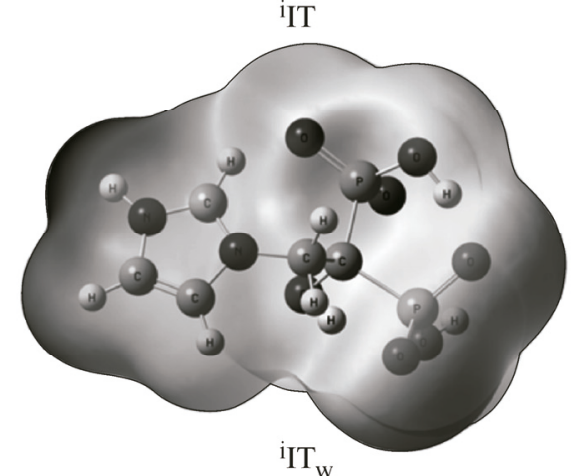

Fig. 5. Molecular electrostatic potential maps for six ZL conformations

tonated structures $(2.94,3.08$, and 4.91$)$, thermal stability of the former is higher than that of the latter. This is in good agreement with the conclusion drawn from the total energy calculations.

Electronic characteristics. Molecular electrostatic potential (MEP) surfaces for six ZL conformations are presented in Fig. 5. Red and blue represent negative and positive electrostatic potentials, respectively. It is known that the MEP surface is useful for understanding the molecular polarity [38 ] and determining the intermolecular interaction, active site, shape and size of the molecule [39]. It gives the information about the net electrostatic effect produced at that point by the total charge distribution (electron+proton) at a point in the space around the molecule [40 ]. Moreover, it can also help to predict the electrophilic and nucleophilic reactions of a wide variety of chemical systems and to study the biological recognition processes and hydrogen bonding interactions [ 41, 42 ].

From Fig. 5, it is seen that the region around the $-\mathrm{OH}$ associated with phosphorus shows the most positive potential for the unprotonated structures, and the N15 atom and the $\mathrm{P}=\mathrm{O}$ double bond possess the maximum negative potential. However, the MEPs of the protonated structures are different from those of the unprotonated ones. With the proton transferred from the oxygen atom to the nitrogen atom of the imidazole ring, a more positive electrostatic potential covers the imidazole ring and the $\mathrm{P}=\mathrm{O}$ double bonds possess a more negative potential. Therefore, it is inferred that the protonated conformations might have better binding affinity for calcified matrices in a bone, such as HA, by the hydroxy group and the $\mathrm{N}-\mathrm{H}$ bond. Moreover, this strong intramolecular charge transfer may be one of the important reasons for the biological activity of ZL protonated conformations. 

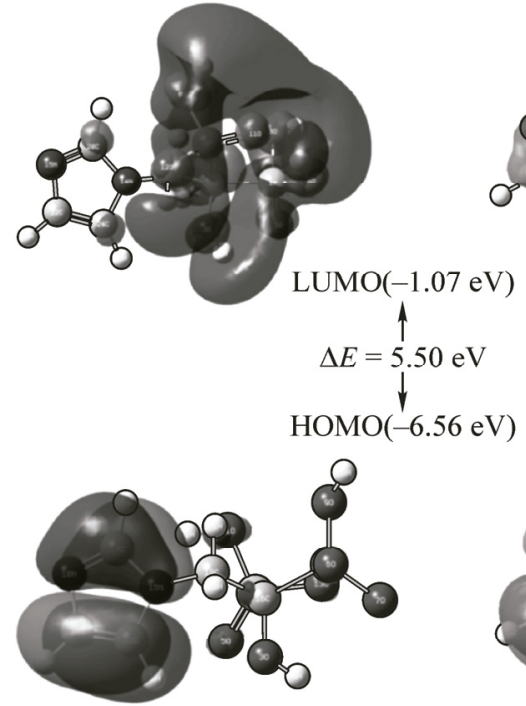

nIM

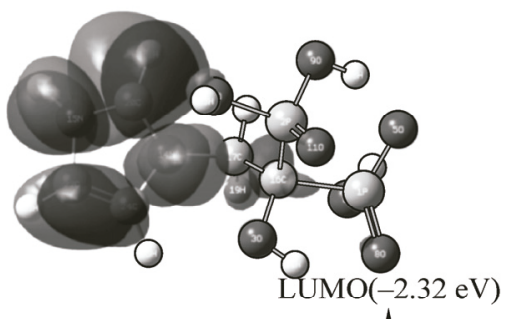

Lumo(-
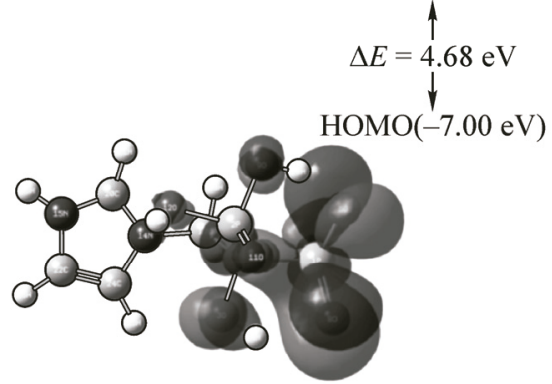

iIM

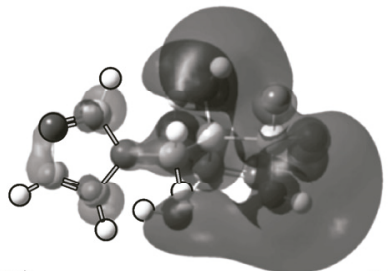

$\operatorname{LUMO}(-0.94 \mathrm{eV})$

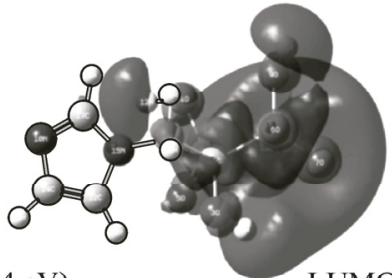

$\operatorname{LUMO}(-1.20 \mathrm{eV})$

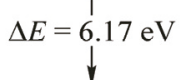

$\mathrm{HOMO}(-7.11 \mathrm{eV})$

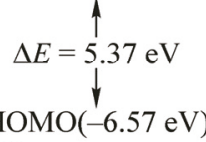

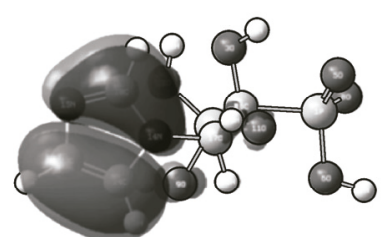

nIT

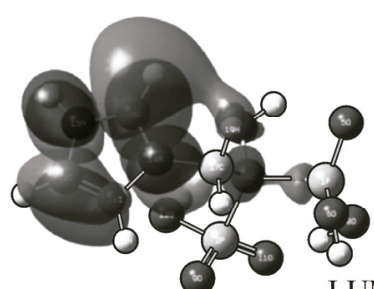

LUMO $(-2.10 \mathrm{eV})$

$\Delta E=5.10 \mathrm{eV}$

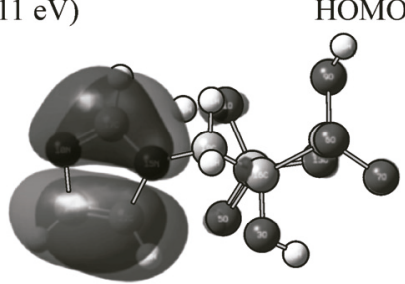

$\mathrm{nIT}_{\mathrm{w}}$

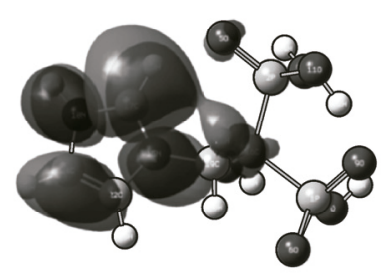

$\operatorname{LUMO}(-2.02 \mathrm{eV})$

$\Delta E=4.92 \mathrm{eV}$

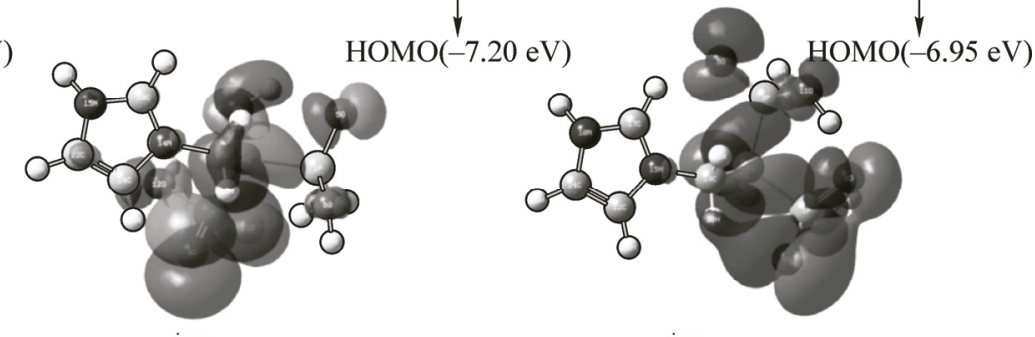

${ }^{\mathrm{i}} \mathrm{IT}_{\mathrm{w}}$

Fig. 6. Frontier molecular orbitals (HOMO and LUMO) and energy levels for six ZL conformations

As is well known, the highest occupied molecular orbital (HOMO) and the lowest unoccupied molecular orbital (LUMO) are the main orbitals taking part in chemical stability and play an important role in characterizing chemical reactions [43 ]. To a certain extent, the HOMO electron density and energy can be employed to represent the stability to donate the electron while the LUMO electron density and energy represent the ability to obtain the electron. Usually, the atoms with a higher HOMO density should have a stronger ability for detaching electrons, whereas the atoms with more occupation of LUMO should more easily gain electrons. The electronic absorption corresponds to the transition from the ground to the first excited state and is mainly described by one electron excitation from the HOMO to the LUMO. The energy gap between the HOMO and the LUMO is a critical parameter in determining the molecular stability [43,44], biological activity [45], and optical properties [46]. In general, a molecule with a smaller frontier orbital gap is more polarizable, and it has a lower kinetic stability and a higher chemical reactivity.

Frontier molecular orbitals (HOMO and LUMO) and energy levels of different ZL conformations are displayed in Fig. 6. It is clear that the energy gaps of the unprotonated conformations are higher 
than those of the protonated conformations by $0.82 \mathrm{eV}, 1.07 \mathrm{eV}$, and $0.45 \mathrm{eV}$ for IM, IT, and $\mathrm{IT}_{\mathrm{w}}$, respectively. Therefore, it is concluded that the chemical reactivities of the unprotonated conformations are lower than those of the protonated ones. This is in good agreement with the experimental fact and above discussion. For the unprotonated structures, the HOMOs localize on the imidazole ring and the LUMOs localize mainly on two phosphate groups. On the contrary, for the protonated structures, the HOMOs localize on two phosphate groups and the LUMOs localize on the imidazole ring. In addition, it can also be observed from the maps of FMOs that the electron density transfers from the imidazole ring to the phosphate groups for the unprotonated conformations, and it transfers from the phosphate groups to the imidazole ring for the protonated conformations. This indicates that the protonated and unprotonated ZL conformations have different active sites. Therefore, they have different chemical and biological properties, which is worth of further investigation.

\section{CONCLUSIONS}

The molecular structures and spectroscopic properties of six ZL conformations have been studied by four different DFT methods with four different basis sets. The comparison of the theoretical and experimental data shows that B3LYP/6-31+G* and B3LYP/6-311++G** are relatively more accurate methods for predicting the structures and vibrations of the unprotonated and protonated ZL conformations, respectively. Thermodynamic properties were calculated and the correlations with the temperature were obtained. From the calculated total electron energy it follows that the protonated structures are more stable than the unprotonated ones. Electrostatic potential surfaces and frontier molecular orbitals all showed that there were strong intramolecular interactions and charge transfer within the molecule, which may be one of the reasons for the biological activity of ZL, and the more electronegative nitrogen atom is the active site in the imidazole ring. The chemical reactivities of the unprotonated conformations were lower than those of protonated ones.

This work was financially supported by the National Natural Science Foundation of China (20801024, 21371082), the Natural Science Foundation of Jiangsu Province (BK20141102), the Key Medical Talent Project of Jiangsu Province (RC2011097), and the Public Service Platform for the Science and Technology Infrastructure Construction Project of Jiangsu Province (BM2012066).

\section{REFERENCES}

1. Jung A., Bisaz S., Fleisch H. // Calc. Tiss. Res. - 1973. - 11. - P. $269-280$.

2. Graham R., Russell G. // Bone. - 2011. - 49. - P. 2 - 19.

3. Roda G.A., Martin T.J. // Science. - 2000. - 289. - P. 1508 - 1514.

4. Coxon F.P., Thompson K., Rogers M.J. // Curr. Opin. Pharmacol. - 2006. - 6. - P. 307 - 312.

5. Qiu L., Lin J.-G., Wang L.-Q. et al. // Aust. J. Chem. - 2014. - 67. - P. 192 - 205.

6. Plotkin L.I., Manolagas S.C., Bellido T. // Bone. - 2006. - 39. - P. 443 - 452.

7. Zekri J., Mansour M., Karim S.M. // J. Bone Oncol. - 2014. - 3. - P. 25 - 35.

8. Foresman J.B., Frisch A. Exploring Chemistry with Electronic Structure Methods. 2nd edition. - Gaussian Inc., Pittsburgh, PA, 1996.

9. Kurt M., Sertbakan T.R., Ozduran M. // Spectrochim. Acta A. - 2008. - 70. - P. $664-673$.

10. Ravikumar C., Joe I.H., Jayakumar V.S. // Chem. Phys. Lett. - 2008. - 460. - P. 552 - 558.

11. Ruscica R., Bianchi M., Quintero M. et al. // J. Pharm. Sci. - 2010. - 99. - P. 4962 - 4972.

12. Chernyshev V.V., Shkavrov S.V., Paseshnichenko K.A. et al. // Acta Crystallogr. - 2013. - C69. - P. 263 - 266.

13. Dennington R.D., Ketith T.A., Millam J.M. GaussView 5. - Gaussian Inc., 2008.

14. Frisch M.J., Trucks G.W., Schlegel H.B., Scuseria G.E., Robb M.A., Cheeseman J.R., Nakatsuji H., Caricato M., Li X., Hratchian H.P., Toyota K., Fukuda R., Hasegawa J., Ishida M., Nakajima R., Honda Y., Kilao O., Nakai H., Verven T., Montgomery J.A. Jr., Peralta J.E., Ogliaro F., Bearpark M., Heyd J.J., Brothers E., Kudin K.N., Staroveror V.N., Kobayashi R., Normand J., Ragavachari K., Rendell A., Burant J.C., Tomasi S.J., Cossi M., Rega N., Millam J.M., Klene M., Knox J.E., Cross J.B., Bakken V., Adamo C., Jaramillo J., Gomperts R., Strattmann R.E., Yazyev O., Austin A.J., Cammi R., Ochetrski J.W., Martin R.L., Morokuma K., Zakrazawski V.G., Votn G.A., Salvador P., Dannenberg J.J., Dapprich S., Daniels A.D., Farkas O., Foresman J.B., Ortiz J.V., Cioslowski J., Fox D.J. Gaussian 09, Revision A.02. - Gaussian, Inc., Wallingford CT, 2009.

15. Karaboga F., Soykan U., Dogruer M. et al. // Spectrochim. Acta A. - 2013. - 113. - P. 80 - 91. 
16. Malik M., Michalska D. // Spectrochim. Acta A. - 2014. - 125. - P. $431-439$.

17. Fehér P.P., Purgel M., Joó F. // Comput. Theor. Chem. - 2014. - 1045. - P. 113 - 122.

18. Zhao Y., Truhlar D.G. // J. Chem. Theory Comput. - 2005. - 1. - P. $415-423$.

19. Leverentz H.R., Qi H.W., Truhlar D.G. // J. Chem. Theory Comput. - 2013. - 9. - P. 995 - 1006.

20. Hariharan P.C., Pople J.A. // Theor. Chem. Accounts. - 1973. - 28. - P. 213 - 222.

21. Rassolov V.A., Pople J.A., Ratner M.A. et al. // J. Chem. Phys. - 1988. - 109. - P. 1223 - 1229.

22. Krishnan R., Binkley J.S., Seeger R. et al. // J. Chem. Phys. - 1980. - 72 . - P. 650 - 654.

23. McLean A.D., Chandler G.S. // J. Chem. Phys. - 1980. - 72. - P. $5639-5648$.

24. Andersson M.P., Uvdal P. // J. Phys. Chem. - 2005. - 109. - P. 2937 - 2941.

25. Irikura K.K., Johnson R.D., Kacker R.N. // J. Phys. Chem. - 2005. - 109. - P. 8430 - 8437.

26. Merrick J.P., Moran D., Radom L. // J. Phys. Chem. - 2007. - 111. - P. 11683 - 11700.

27. Tayyari S.F., Holakoei S., Mahdizadeh S.J. // J. Mol. Struct. - 2013. - 1041. - P. 190 - 199.

28. Hill T.L. Introduction to statistical thermodynamics. - N. Y.: Addision-Wesley Publishing Company, 1960.

29. Manaj J.J., Maciewska D., Waver I. // Magn. Reson. Chem. - 2000. - 38. - P. 482 - 485.

30. Yuksek H., Cakmak I., Sadi S. et al. // Int. J. Mol. Sci. - 2005. - 6. - P. 219 - 229.

31. Wolinski K., Hilton J.F., Pulay P. // J. Chem. Soc. - 1990. - 112. - P. 8251 - 8260.

32. Amado A.M., Fiuza S.M., Marques M.P. et al. // J. Chem. Phys. - 2007. - 127. - P. $185104-185114$.

33. Chen L.P. Master Thesis. - Wuxi: Jiangnan University, NO. TQ463, R96, 2013.

34. Juillard A., Falgayrac G., Cortet B. et al. // Bone. - 2010. - 47. - P. 895 - 904.

35. Bai X.Q. Master Thesis. - Chongqing: Chongqing University, NO. TQ463.6, 2005.

36. Qiu L., Liu Q.-Z., Wang Y. et al. // Struct. Chem. - 2015. - 26. - P. 845 - 858.

37. Govindarajan M., Karabacak M. // Spectrochim. Acta A. -2012. - 96. - P. $421-435$.

38. Reed A.E., Weinhold F. // J. Chem. Phys. - 1985. - 83. - P. 1736 - 1740.

39. Petrucci R.H., Harwood W.S., Herring F.G. et al. // Pearson Education Inc., New Jersey, 2007.

40. Thul P., Gupta V.P., Ram V.J. et al. // Spectrochim. Acta A. - 2010. - 75. - P. 251 - 260.

41. Politzer P., Murray J.S. // Theor. Chem. Acc. - 2002. - 108. - P. $134-142$.

42. Luque F.J., Lopez J.M., Orozco M. // Theor. Chem. Acc. - 2000. - 103. - P. 343 - 345.

43. Fleming I. Frontier Oribitals, Organic Chemical Reactions. - London: Wiley, 1976.

44. Aihara J. // J. Phys. Chem. - 1999. - 103. - P. 7487 - 7495.

45. Sajan D., Udaya Lakshmi K., Erdogdu Y. et al. // Spectrochim. Acta A. - 2011. - 78. - P. 113 - 121.

46. Eren B., Unal A. // Spectrochim. Acta A. - 2013. - 103. - P. 222 - 231. 